Board of Governors of the Federal Reserve System

\author{
International Finance Discussion Papers
}

Number 536

January 1996

\title{
REGIME SWITCHING IN THE DYNAMIC RELATIONSHIP BETWEEN THE FEDERAL FUNDS RATE AND INNOVATIONS IN NONBORROWED RESERVES
}

\author{
Chan Huh
}

NOTE: International Finance Discussion Papers are preliminary materials circulated to stimulate discussion and critical comment. References in publications to International Finance Discussion Papers (other than an acknowledgment that the writer has had access to unpublished material) should be cleared with the author or authors. 


\begin{abstract}
This paper examines the dynamic relationship between changes in the funds rate and nonborrowed reserves within a reduced form framework that allows the relationship to have two distinct patterns over time. A regime switching model á la Hamilton (1989) is estimated. On average, CPI inflation has been significantly higher in the regime characterized by large and volatile changes in funds rate. Innovations in money growth are associated with a strong anticipated inflation effect in this high inflation regime, and a moderate liquidity effect in the low inflation regime. Furthermore, an identical money innovation generates a much bigger increase in the interest rate during a transition period from the low to high inflation regime than during a steady high inflation period. This accords well with economic intuition since the transition period is when the anticipated inflation effect initially gets incorporated into the interest rate. The converse also holds. That is, the liquidity effect becomes stronger when the economy leaves a high inflation regime period and enters a low inflation regime period.
\end{abstract}




\title{
REGIME SWITCHING IN THE DYNAMIC RELATIONSHIP BETWEEN THE FEDERAL FUNDS RATE AND INNOVATIONS IN NONBORROWED RESERVES
}

\author{
Chan Huh'
}

Introduction

Many recent studies document a great deal of instability in the observed strength of the liquidity effect--i.e., the negative dynamic relationship between nominal interest rates and monetary aggregates (e.g., Thornton, 1988, Leeper and Gordon, 1992). Along with the particular monetary aggregate used, the sample period emerges as a crucial factor in determining the strength of the estimated liquidity effect. Even in studies with affirmative findings, there is evidence suggesting instability in the relationship seen in empirical models of conventional, as well as new, varieties. As a result, some researchers pay close attention to the sample period. For example, this concern could be a key reason why some limit the sample of their study to a short, particular period, rather than using a longer sample (e.g., Leeper and Gơrdon (1993)). ${ }^{2}$

${ }^{1}$ The author is an economist in the Division of International Finance, Federal Reserve Board, and the Federal Reserve Bank of San Francisco. I would like to thank seminar participants at the Federal Reserve Bank of San Francisco, the Board of Governors, the Fall 1995 System Conference on Macroeconomics, and the Bank of Korea, as weil as John Judd, Ken Kasa, Gienn Rudebusch, Tom Sarigent, Míchael Bơdinin, Philip Jefferson, and Jon Faust for helpful comments and suggestions. Judy Kim provided able research assistance. Any remaining enrors are my own. The views expressed here are those of the author and do not necessarily reflect those of the Federal Reserve Bank of San Francisco or the Board of Governors of the Federal Reserve System. Please address correspondence to: Chan Huh, Mail Stop \#23, Division of International Finance, Board of Governors of the Federal Reserve System, Washington, DC 20551. Email: huhc@frb.gov, tel.:202-452-2296.

2 Mishkin (1981) finds instability in the coefficients of the model used in testing a negative relationship between the unanticipated parts of the short-term interest rate and monetary aggregates. Thornton's (1988) result suggests heteroskedasticity. Eichenbaum and Christiano (1992), and Christiano (1994) offer a similar observation regarding the "money supply" equation used to net out the anticipated component of change in the monetary aggregates. Pagan and Robertson (1994) document the presence 
This study, therefore, focuses on the observation that the sample period has a critical influence on estimates of the liquidity effect. Applying the stochastic regime changing model developed by Hamilton (1989), I estimate a bivariate regression equation of interest rates and reserves that ailows for potential systematic shifts in the relationship across different periods. This paper investigates the potential influence of such regimes on measures of the liquidity effect. Finding evidence of a systematic and significant shift in the relationship will offer an explanation of inconsistencies seen in the empirical liquidity effect literature.

Shifts in inflation momentum over time are conjectured to be an important underlying factor behind potential shifts in the interest rate-reserves relationship. ${ }^{3}$ The theoretical reason for deeming the inflation tendency important is straightforward. From the Fisher effect, nominal interest rates partly reflect anticipated inflation. Thus, the inflationary momentum should influence the extent to which the anticipated inflation component dominates movements in observed nominal interest rates in response to changes in some monetary aggregates. ${ }^{4}$

The federal funds rate (FYFF) and nonborrowed reserves (NBR) are used in this

of $\mathrm{ARCH}$ in the residuals of the equations of the VAR system used to examine impulse responses for the liquidity effect.

${ }^{3}$ Shifts in inflationary momentum could arise due to several reasons that are not mutually exclusive. They are; (i) changes in the inflationary tendency of monetary policy, (ii) inflationary impuises coming from supply shocks, and (iii) changes in market participants' views of the inflation trend.

${ }^{4}$ See, Fuerst (1992), Christiano and Eichenbaum (1992), Coleman, Gilles, and Labadie (1992, 1994) for examples of a flexible price general equilibrium modeling approach to the liquidity effect. Theirs is a cash-in-advance framework with segmented (financial and goods) markets. A liquidity premium arises because money is valued differently in the financial market than in the goods market.

LeRoy (1984) offers a model with a money-in-the-utility function specification, in which the existence of a liquidity effect critically depends on the serial correlation properties of the exogenous money injections. A change in the current money supply will have different effects depending on what is expected to follow in subsequent periods. 
study. There is a long list of papers that focus on these two variables (for example, Strongin (1989), Christiano and Eichenbaum (1992), Christiano, Eichenbaum and Evans (1994), and Hamilton (1994)). Here, however, I relax the usual single regime assumption of the existing literature and instead estimate reduced form equations of interest rates and reserves akin to Mishkin (1982), adding the stochastic regime shifting feature. ${ }^{5}$ Then, I examine whether there is a noticeable change in extant findings of the empirical liquidity effect literature. ${ }^{6}$ The model is estimated using first differenced monthly data for the 1963-1993 sample period. The 'unanticipated' growth rate of NBR, as derived in Mishkin (1982), is used as the money measure and it will be referred as unbr.

Results indicate that the regime switching model fits the data better than a single regime model. The two disjoint sample periods, each best described by the two regime specific models, differ in terms of average change in the interest rate and money growth, as well as the volatility of the rate changes. More importantly, the historical CPI inflation rate has been significantly higher during periods dominated by a larger average change and more volatile regime. Based on this, the two regimes will be referred to as the high or low inflation regimes. The 1970 s and early ' 80 s show a greater concentration of high inflation regimes.

\footnotetext{
${ }^{5}$ Thus, this model might be regarded as a two-state version of the single equation model of Mishkin (1982). There has been progress in empirical liquidity effect literature since early 1980 as shown, for example, in Pagan and Robertson (1995). However, the possibility of a systematic change in regimes as modelled in this paper has not been considered. Since this work is in the spirit of a preliminary investigation on the importance of regime switching, a single equation framework is adopted.

${ }^{6} \mathrm{Jefferson}(1994)$ applies a similar regime switching framework to issues of monetary policy. However, his focus is on assessing various qualitative indexes of policy stance. For general applications see Hamilton (1989, 1994), Filardo (1994), Boldin (1992), Kim (1994), and Ammer and Brunner (1994).
} 
Interest rate responses to an innovation in money growth in the two regimes clearly diverge. The low inflation regime is associated with a more significant negative short-run comovement between the interest rate and unbr (i.e., liquidity effect). In response to an innovation in reserve growth, cumulative changes in the interest rate remain negative for ten months in the low inflation regime. In other words, in a regime of low inflation, the interest rate will remain below the level it was at before the initial period for at least ten months following a positive unbr shock.

In contrast, in a regime of high inflation the overall impact of a reserve innovation will be countered quickly and will thus be more short-lived. For the same innovation, the interest rate rises sharply above the initial level within four months of the initial period. This appears to illustrate an overwhelming anticipated inflation effect, in contrast to the modest liquidity effect seen in low inflation periods.

An examination of dynamic properties of the estimated model around regime switching periods indeed yields economically sensible results. It shows the interest rate rising by a large amount as the economy enters a high inflation (regime) period after being in a low inflation period for awhile. That is, the net increase in the rate following an innovation in money during such a transition period is much bigger than that seen for a persistently high inflation sample period. This is intuitive because the transition period is when there is an increase in inflationary momentum as the result of both a higher inflation expectation and inflation risk premia getting initially incorporated into interest rates. The converse holds, i.e., the interest rate falls by a large amount as the economy enters into a low inflation (regime) 
period after being in a high inflation period for awhile. ${ }^{7}$ This observation further suggests that it is reasonable to associate identified regime periods with high and low inflation.

Such disparate dynamic responses of the interest rate across the two regimes could explain why studies using different sample periods find positive, as well as negative, comovement patterns between money and interest rates. A relatively large concentration of observations from a particular regime could influence the characteristics of the liquidity effect. For example, Pagan and Robertson (1994) document such a disparity in impulse responses of the funds rate to a nonborrowed reserve shock for different sample periods. They found that the size of the bounce back in the funds rate following an initial negative response to be much larger for the sample from 1974 to 1993, compared to that of the 1959 to 1993 sample. In the shorter sample, the size of the bounce back was even larger than the initial fall in the rate. Characteristics of the shorter sampie might reflect those of high inflation regime observations, which make up a larger proportion of the full sample in the post-1974 period.

Finally, the goal of the exercises in this paper is to document regime switches in data rather than to examine why and how the regimes switch. However, this paper's finding naturally raises a second set of questions. In that regard, any suggestion given here is speculative. For instance, one cannot interpret each regime as unambiguously capturing the

\footnotetext{
${ }^{7}$ Consider two distinct histories. In the first, a low inflation regime prevails before and after the reserve innovation. In the second history, the economy remains in a high inflation regime up to the innovation date $t$, then switches to and remains in a low inflation regime thereafter. It turns out that the magnitude of the cumulative fall in the interest rate of history two is much larger than that of history one. This difference can be thought of as an added benefit (deflationary bonus) when the regime switches from a high to low inflation type. Conversely, there seems to be an inflation penalty. That is, the interest rate increase associated with the low to high inflation regime switch is bigger than that associated with the scenario where a high inflation regime persists throughout.
} 
monetary policy stance, i.e., shifts in the reserve supply curve. However, shifts in inflation momentum over time do appear to be an important underlying factor behind shifts in the interest rate-reserves relationship. Further study, with a more elaborate identification scheme, might yield informative results.

Sections II and III offer a description of the model and estimation results. Dynamic responses of the interest rate to an innovation in money growth for each regime are examined in Section IV. Section V offers a brief discussion of the findings and Section VI concludes.

\section{Model Specification}

The following model represents an extension of the univariate model of Hamilton (1989),

$$
r_{i}=\mu_{q}\left(s_{i}\right)+\sum_{j=1}^{l} \beta_{p}^{j}\left(s_{i}\right)\left[r_{i-j}-\mu_{i}\left(s_{i-j}\right)\right]+\sum_{i=0}^{k} \beta_{m}^{i}\left(s_{i}\right) u n b r_{i=i}+\epsilon_{i}\left(s_{i}\right)
$$

where

$$
\epsilon_{\imath} \sim N\left(0, \sigma\left(S_{t}\right)\right)
$$

Here $r$ denotes changes in interest rate and unbr denotes unanticipated growth in money. $S_{\mathfrak{t}}$ is the regime index, indicating what regime is in place in period t. Both the average level of $r\left(\right.$ i.e., $\left.\mu_{r}\right)$ and its interaction with its own lags and monetary aggregates depend on the regime in place at any given period t (i.e., $\beta\left(S_{t}\right)$ 's). The error terms are assumed to be from two normal distributions with zero means, and the variance of each distribution is regime dependent (i.e., $\sigma(S)^{\prime}$ s). Thus, heteroskedasticity is a property of the model. The current regime $S_{1}$ is assumed to be unobservable, but agents can draw probabilistic inferences. That 
is, agents can calculate $P\left(S_{t}\right)$ given the histories of the observable variables $r$ and $u n b r$. Two types of regimes are posited, type $\mathbf{H}$ and type $\mathbf{L}$. Switches between the two are assumed to be governed by the following two-state Markov process with constant transition probabilities;

$$
\begin{gathered}
\operatorname{prob}\left(S_{t}=L \mid S_{t-1}=L\right)=p, \\
\operatorname{prob}\left(S_{t}=H \mid S_{t-1}=L\right)=1-p, \\
\operatorname{prob}\left(S_{t}=H \mid S_{t-1}=H\right)=q,
\end{gathered}
$$

and

$$
\operatorname{Prob}\left(S_{t}=L \mid S_{t-1}=H\right)=1-q
$$

This regime switching property is the main innovation of the model in this paper.

The money variable (unbr) used in the estimation is the unanticipated change in money derived along the line of Mishkin (1982).

That is,

$$
u n b r_{t} \equiv \Delta n b r_{t}-\Delta n b r_{t}^{e}
$$

where

$$
\Delta n b r_{t}^{e} \equiv E\left(\Delta n b r_{t} \mid X_{t-1}\right)
$$

and

$$
X_{t-1}=\left(\Delta i p_{t-i}, \Delta c p i_{t-i}, \Delta r_{t-i}, \Delta n b r_{t-i} \mid i=1,2,3, \ldots\right)
$$

To be specific, the anticipated monthly growth in NBR for each period is obtained by 
regressing it on the information set consisting of six lagged values of the growth rate of industrial production, CPI inflation, changes in the funds rate, and the growth rate of NBR. ${ }^{8}$

(2) $\Delta n b r_{t}^{e}=a+\sum_{i=1}^{6} \beta_{i}^{i p} \Delta i p_{t-i}+\sum_{i=1}^{6} \beta_{i}^{c p i} \Delta c p i_{t-i}+\sum_{i=1}^{6} \beta_{i}^{r} \Delta r_{t-i}+\sum_{i=1}^{6} \beta_{i}^{n b r} \Delta n b r_{t-i}$.

Figure 1 intuitively describes the reserve market situation that is envisioned by the current two regime model. ${ }^{9}$ Suppose that the nonborrowed reserve supply is inelastic but can shift between two levels, $\mathrm{H}$ and $\mathrm{L}$. Also suppose that there are two distinct demands for the reserves of $\mathrm{H}$ and $\mathrm{L}$. Over time, we will observe market clearing pairs of nonborrowed reserves and the funds rates as both the supply and demand are buffeted by respective shocks. Furthermore, the observed data will likely form two distinct clusters. Suppose the two following conditions are met. First, each regime is sufficiently persistent so that we will have a number of observations, contiguous in time, that are generated under similar circumstances. At the same time a shift between the two regimes occurs frequently enough so that we will have a reasonable number of observations for each regime period. Once these conditions are met. the dichotomy scheme adopted here will fit the data better.

\footnotetext{
${ }^{8}$ Strictly speaking, this procedure involves the assumption that the contemporaneous money demand factors are not important. Nonetheless, the focus of the paper is to examine a divergence in the bivariate dynamic pattems, or the liquidity effect. Thus, for expositional purposes this assumption is retained. The current model will have a better chance of capturing the general tendencies of the interaction between the funds rate and the reserve at two distinct intersection points if such shifts occur reasonably frequently.

${ }^{9} \mathrm{We}$ are ignoring the borrowed component in total reserves for reasons of brevity.
} 


\section{Estimation Results}

Two versions of (1) are estimated using the numerical maximum likelihood method described in Hamilton (1994). The first specification assumes that there is a distinct shift in the average rate of change in $r$ across the two regimes, i.e., $\mu_{r}(\mathbf{H})>\mu_{r}(\mathbf{L})$. However, no such restriction of a distinct shift is imposed on unbr. The second specification, shown below, imposes that both the timing of the regime shift and the magnitude of average rates of changes in each regime be identical for $\mathrm{r}$ and $u n b r$.

$$
r_{t}=\mu_{r}\left(s_{t}\right)+\sum_{j=1}^{4} \beta_{r}^{j}\left(s_{t}\right)\left[r_{t-j}-\mu\left(s_{t-j}\right)\right]+\sum_{i=0}^{3} \beta_{m}^{i}\left(s_{t}\right)\left[u n b r_{t-i}-\mu\left(s_{t-i}\right)\right]+\varepsilon_{t}\left(s_{t}\right) .
$$

The models are estimated using first differenced monthly data on FYFF, and unbr, where both series are measured by their monthly averages. ${ }^{\text {io }}$ Estimation results are given in Tables 1 and 2 for models I (the first specification) and II (the second specification). Standard errors of estimated coefficients are given in parentheses.

Before going further, we need to address the question of whether or not the two regime specification versus a single regime alternative is most appropriate. This is done by

\footnotetext{
${ }^{10}$ The sample period is from 1963:1 to $1993: 12$ and the series were transformed as follows. First, $R_{4}$

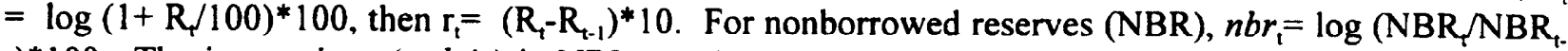
$\left.{ }_{1}\right)^{*} 100$. The innovations (unbr's) in NBR are derived by regressing $n b r_{t}$ on the variables shown in (2). The regression was run recursively with the starting date of 1959:6. This ensures that the estimation of (1) for period $t$ does not involve any information beyond period $t$. This procedure could give rise to a generated regressor problem and hence the standard errors of the estimated coefficients could understate the true extent of uncertainty. However, results do not change perceptibly when equation (1) was estimated using the actual changes in nonborrowed reserves instead of the unanticipated money of equation (2) (Huh (1995)).
} 
using the likelihood ratio test of the two specifications as suggested by Garcia (1992)." This test overwhelmingly rejects the single regime null hypothesis. ${ }^{12}$

A negative comovement pattern between $r$ and $u n b r$, (i.e., the liquidity effect) holds in both regimes. For model I (Table 1) the coefficients on contemporaneous money growth are significantly negative for both regimes. A negative contemporaneous comovement is more pronounced in regime $\mathbf{L}$ (significant at 1 percent) than in regime $\mathbf{H}$ (significant at 5 percent) for model I. In model II, the contemporaneous coefficient is significant only in regime $\mathbf{L}$ (at 1 percent). A negative effect persists even after one month in regime $\mathbf{L}$, but not in regime $\mathbf{H}$ (i.e., $\beta_{m}^{\prime}$ is significant at 10 percent) for model I. A further discussion of the dynamic response of the interest rate to a change in money will be given later.

Figure 2 plots the inferred probability that regime $\mathbf{H}$ was in place in any given month based on information up to each period. This is based on model I. Data generated from the other specification (model II) does not differ much. Regime $\mathbf{H}$ seems to have been dominant during several periods. The most noticeable is the sample period from 1979 to 1982 . The sample period of $1973-75$ is also prominent. Regime $\mathbf{H}$ has been in three additional periods, 1969-70, 1984-85, and early 1987.

To see if there is a systematic link between inflation and each of the two regimes, Figure 3 shows annual CPI inflation (a 7 month moving average of annualized monthly

\footnotetext{
"'The single regime model is not identified under the null hypothesis and consequently the likelihood ratio has a non-standard Chi-square distribution. For more discussion see Garcia (1992) and Hansen (1993).

${ }^{12}$ The difference in the likelihood function values is large. For Model I, the likelihood value for a single regime version was 714 compared with 594.7 from Table 1. This strongly suggests that the four lag specification is a very poor one for single regime models. For example, the value falls to 670 from 710 when 12 lags are included.
} 
changes in CPI) along with the inferred probability of regime $\mathbf{H}$. There is a high degree of coherence between the actual high inflation periods and regime $\mathbf{H}$ periods. With the exception of the 1984-85 interval, each regime $\mathbf{H}$ period coincides with a rising or peaking CPI inflation.

To be more specific, regime specific samples are constructed based on whether $\mathrm{P}(S(\mathrm{t})$ $=\mathbf{H}$ ), shown in Figure 2, is greater than 0.5 or not. The average CPI inflation for periods belonging to regime $\mathbf{L}$ (290 out of the total 365 months) was 4.29 percent. On the other hand, the average for the 75 months belonging to the type $\mathbf{H}$ regime was 8.31 percent. The standard errors for each period are 2.2 (type L) and 3.2 (type H). Average growth in money divided into two subsamples exhibits a similar divergence in characteristics. Average growth in nonborrowed reserves during the regime $\mathbf{H}$ period is 2.8 times larger than in regime $\mathbf{L}$. With regard to the variability measured in terms of standard errors of growth rates, it is 1.5 times more volatile in regime $\mathbf{H}$ than in regime $\mathbf{L}$ periods. Results also indicate that a larger average change in the interest rate is associated with a significantly larger variability. That is, $\sigma^{2}(\mathbf{H})>\sigma^{2}(\mathbf{L})$.

The estimates of the transition probabilities (p's and q's) suggest that the low inflation regime has been about 10 percent more persistent. Overall, regime $\mathbf{L}$ has been more prevalent than regime $\mathbf{H}$ in the period between 1964-1993. The expected durations are 39 and 10 months for $\mathbf{L}$ and $\mathbf{H}$ regimes, respectively. ${ }^{13}$

\footnotetext{
${ }^{13}$ Because the model is specified in terms of changes in the interest rate, it is conceivable that the model might identify periods during which the interest rate is raised from 1 to 2 percent as belonging to the high inflation regime! This would be absurd based on historical experience which suggests that such low funds rates would be compatible only with very low inflation. However, it is also historically the case that the funds rate is not changed by a large amount during periods of low and stable inflation. For example, the ranges of change in the funds rate (measured in basis points) during regime $\mathbf{L}$ and $\mathbf{H}$ periods
} 


\section{Dynamic Effect of Reserve Intervention on the Interest Rate}

\section{Regime Specific Responses}

A clearer divergence between the two regimes emerges when we examine their dynamic properties. The quantitative experiment involves tracing effects of equal reserve interventions for each regime over time. We will use model I as the example. Due to the regime switching structure of the models, dynamic responses crucially depend on which regime is in place at period $t$, the period when the reserve innovation takes place.

Furthermore, in tracing these effects, we have to allow for the possibility of regime switching over time.

First, we assume that the economy has been in the same regime for five months (period $\mathrm{t}-4$ through period $\mathrm{t}$ ) with no innovation in the money supply $\left(u n b r_{\mathrm{i}}=0, \mathrm{i}=\mathrm{t}-4, \ldots \mathrm{t}-1\right) .^{14}$ Then, we subject the economy to a one-time innovation in money (i.e., unbr $>0$ ) and trace out paths of interest rate responses.

Suppose regime $\mathbf{H}$ is in place in period $t$. Then there are two possible values for $r$ in

are respectively $[-70,73]$ and $[-265,305]$. These ranges do not include extreme values at either ends. Two regime periods are identified in the same way as in the text. For the sample period used in the study, the hypothetical case of seeing a large change in the interest rate when inflation is low and stable does not exist. Furthermore, the size of rate change is only part of the properties used for regime determination. Thus, this potential pitfall of the model specification does not pose a problem for the current analysis.

${ }^{14}$ To be more precise, the interest rate responses also depend upon the relevant past history of the regimes. Suppose that we are in regime $\mathbf{H}$ in period $t$ when there is a surprise increase in nonborrowed reserves. The shape of the interest rate responses to this shock in future periods (i.e., $t+1, t+2, \ldots$ ) will depend on how we arrived in period $t$, or the past realizations of the regimes. That is, the response of the interest rate when $S(t-4)=H, S(t-3)=H, S(t-2)=H$. and $S(t-1)=H$ will be different from that when $S(t-4)=H$, $S(t-3)=H, S(t-2)=L$, and $S(t-1)=L$. For simplicity, this complication will not be considered. 
period $\mathrm{t}+1$ for each of the possible regimes, i.e., $r_{\mathrm{t}+1}(\mathrm{~S}(\mathrm{t}+1)=\mathbf{H} \mid \mathrm{S}(\mathrm{t})=\mathbf{H})$ and $r_{\mathrm{t}+1}(\mathrm{~S}(\mathrm{t}+1)$ $=\mathbf{L} \mid \mathbf{S}(t)=\mathbf{H})$. Given that regime $\mathbf{H}$ is in period $t$, the probabilities for each of the two values are $q$ and $1-q$, respectively. Since the regime can shift in each period, there are $2^{k}$ distinct paths along which $r$ response can evolve $\mathrm{k}$ periods hence. For each of these paths, we can assign probabilities conditional on the regime of period t. Furthermore, we can determine the most likely path by finding an outcome with the highest probability of occurring in each period. For the estimated values of $\mathrm{p}$ and $\mathrm{q}$ and for $\mathrm{k}$ less than 31 , the most likely sequence of regimes over time is $\mathrm{S}(\mathrm{t})=\mathrm{S}(\mathrm{t}+1)=\mathrm{S}(\mathrm{t}+2)=\ldots .=\mathrm{S}(\mathrm{t}+\mathrm{k})=\mathbf{H}$. This path has the largest probability of $\mathrm{q}^{\mathrm{k}}$ of all sequences with the length $\mathrm{k}$ when regime $\mathbf{H}$ is in the initial period. ${ }^{15}$ Similarly, the most likely sequence of regimes over time is $S(t)=S(t+1)$ $=\mathrm{S}(\mathrm{t}+2)=\ldots .=\mathrm{S}(\mathrm{t}+\mathrm{k})=\mathbf{L}$, when period $\mathrm{t}$ regime is $\mathbf{L}$. This event has the largest conditional probability $\mathrm{p}^{\mathrm{k}}$.

Figure 4 shows the cumulative changes in $r$ in response to a $u n b r$ shock for each case described above. The shock is assumed to be one-time, that is, growth in money is held to zero before and after period t. Its size is $2 \times \sigma_{\mathrm{m}}(\mathbf{H})$, i.e., two times the standard error of growth in nonborrowed reserves in the historical regime $\mathbf{H}$ sample period. The standard error is 2.11 percent.

The responses of changes in the interest rate in the two regimes clearly diverge. A

\footnotetext{
${ }^{15}$ This can be shown as follows: Since both $p$ and $q$ are greater than $0.5, q^{k}>q^{k-1}(1-q)$. The former is the probability that regime $\mathbf{H}$ remains throughout $k$ periods starting in $t$. However, $p$ is greater than $q$ according to the estimates shown in Table 3 . Thus, it is possible that the probability associated with the event that the regime is switched from $\mathbf{H}$ to $\mathbf{L}$ early on and the economy remains in regime $\mathbf{L}$ thereafter would be greater than that of the event of regime $\mathbf{H}$ remaining in place throughout $\mathbf{k}$ periods. The mostly likely candidate is when the switch from $\mathbf{H}$ to $\mathbf{L}$ occurs in period $t+1$ and regime $\mathbf{L}$ remains thereafter. The associated probability is $(1-q) p^{k-1}$. It turns out that $q^{k}$ is greater than $(1-q) p^{k-1}$ for $k$ less than 31 , for the estimated values of $p$ and $q$.
} 
negative interest rate response lasts less than three months in regime $\mathbf{H}$, then gets reversed. The relative size of responses for each regime is misleading because they are not adjusted for estimation uncertainty. For example, confidence intervals constructed allowing for 1.5 times the standard error of each coefficient for the first two periods for regime $\mathbf{H}$ are $[0.29,-10.06]$, $[8.46,-9.30]$ and for regime $\mathbf{L},[-0.02,-1.41]$ and $[-0.41,-3.14] .{ }^{16}$ That is, for regime $\mathbf{H}$, the confidence interval for the response of $r$ in the initial period includes zero. On the other hand, similar confidence bands of $r$ for regime $\mathbf{L}$ do not include zero for at least two periods. Starting in the fourth month after the initial shock, the interest rate starts rising sharply above the initial level. That is, the cumulative change in the interest rate turns positive. In contrast, the cumulative changes in the interest rate remain negative for ten months in regime $\mathbf{L}$. In other words, the interest rate will remain below the level it was at before the initial period for at least ten months following the unexpected increase in nonborrowed reserves. The duration of the liquidity effect is at least three times longer in the regime $\mathbf{L}$ period compared to regime H. The overall impact of a reserve innovation will be countered quickly and thus will be more short-lived in regime $\mathbf{H}$ than in regime $\mathbf{L}$. The former appears to illustrate an overwhelming anticipated inflation effect. in contrast to the modest liquidity effect seen in the low inflation periods. Thus, it is not surprising that studies using different sample periods find both positive and negative comovement patterns between money and interest rates.

This observation confirms a finding regarding the impulse response pattern between

\footnotetext{
${ }^{16}$ The upper and lower bounds for regime $S$ are calculated as follows: upper $(S)=(u m b r) \times\left(\beta_{m}^{0}(S)+1.5 \times\right.$ s.e. $\left.\left(\beta_{m}^{0}(S)\right)\right)+\mu(S)$, and lower $(S)=($ unbr $) \times\left(\beta_{m}^{0}(S)-1.5 \times\right.$ s.e. $\left.\left(\beta_{m}^{0}(S)\right)\right)+\mu(S)$. The choice of the $5 \%$ confidence level criteria and the error band construction are somewhat arbitrary. This analysis is meant to be suggestive.
} 
the funds rate and nonborrowed reserves by Pagan and Robertson (1994). In response to an innovation in reserves, the funds rate initially falls, but is shortly followed by a bounce back. They find the size of this bounce back to be much larger for the sample from 1974 to 1993 , compared to that of the 1959 to 1993 sample. Remarkably, the size of the bounce back is larger than the initial fall in the rate of the first sample. ${ }^{17}$

A high bounce back is a distinct characteristic of regime $\mathbf{H}$. According to Figure 2, the post-1974 sample has a high concentration of observations belonging to the high inflation regime compared to the earlier period. Thus, as a whole, the latter sample period would exhibit more regime $\mathbf{H}$ patterns than the 1959-1993 sample. It is interesting to note that the reduced form equation could capture properties identified by a more fully specified multivariate system of equations once the potential shifts in the regimes are allowed.

\section{Dynamic Responses when Regimes Switch}

The quantitative analysis so far focuses on cases when one regime persists. Further examination of dynamic responses of the interest rate in cases when regimes switch also yields interesting results. Though this paper's analysis does not explain why regime switches occur, it does offer an insight on what happens when the regime switches take place. We then use this to see whether the estimated model is economically sensible.

Suppose that the economy has been in a low inflation regime, or regime $\mathbf{L}$ for awhile. Furthermore, the monetary authority has continued to exploit a favorable 'liquidity effect' environment by generating a series of reserve innovations as described above. As a

\footnotetext{
${ }^{17}$ Figures 4C, 4D, 8A, and 8B of Pagan and Robertson (1994).
} 
consequence, a shift from a low inflation to a high inflation regime takes place in period $t+1$ and remains thereafter. However, the reserve supply innovation is assumed to take place in period $\mathrm{t}$ as before. This scenario is represented by the sequence $\{\mathrm{S}(\mathrm{t}-4)=\mathrm{S}(\mathrm{t}-3)=. .=\mathrm{S}(\mathrm{t})=$ $\mathbf{L}, \mathbf{S}(\mathrm{t}+1)=\mathbf{S}(\mathrm{t}+2)=\ldots .=\mathbf{H}\}$, and will be referred to as the switch $(\mathbf{L} \mid \mathbf{H})$.

Figure 5 compares the resulting cumulative changes in the funds rate to those cases when the regime remains in $\mathbf{H}$ and $\mathbf{L}$ throughout for the same $u n b r_{\mathrm{t}}$. The switch $(\mathbf{L} \mid \mathbf{H})$ is associated with the largest increase in the funds rate out of the three cases. It even surpasses the increase in the regime $\mathbf{H}$ case. Six months after the shock (i.e., in period $t+7$ ), the cumulative increase in the interest rate in the switch $(\mathbf{L} \mid \mathbf{H})$ case is about three times larger than that in the regime $\mathbf{H}$ case. That is, the rise in the interest rate in the period following a transition from regime $\mathbf{L}$ to $\mathbf{H}$ is even larger than the increase in the rate when regime $H$ remains in place throughout. This extra increase in the rate can be thought of as an inflation penaity, or an added cost of entering a high infiation regime.

Symmetrically, we can consider the case of switch $(\mathbf{H} \mid \mathbf{L})$. Suppose the economy has been in a high inflation regime, or regime $\mathbf{H}$, for awhile but the monetary authority has successfully conveyed its intention to restrain inflation in the future. As a consequence, a shift from a high to low inflation regime takes place in period $t+1$ and remains thereafter. This scenario is represented by the sequence $\{\mathrm{S}(\mathrm{t}-4)=\mathrm{S}(\mathrm{t}-3)=. .=\mathrm{S}(\mathrm{t})=\mathbf{H}, \mathrm{S}(\mathrm{t}+1)=\mathrm{S}(\mathrm{t}+2)$ $=\ldots=\mathbf{L}\}$.

Figure 6 compares the resulting cumulative changes in the funds rate to those cases when the regime remains in $\mathbf{H}$ and $\mathbf{L}$ throughout. The switch $(\mathbf{H} \mid \mathbf{L})$ is associated with the largest decrease in the rate out of the three cases. even surpassing the fall in the regime $\mathbf{L}$ 
case. Six months after the shock (i.e., in period $t+7$ ), the cumulative decrease in the interest rate associated with the switch $(\mathbf{H} \mid \mathbf{L})$ case is about 20 times that of the regime $\mathbf{H}$ case. That is, the magnitude of a fall in the interest rate in the period immediately following a transition from regime $\mathbf{H}$ to $\mathbf{L}$ is even larger than that of a decrease in the rate in the regime $\mathbf{L}$ period. This can be thought of as a deflation bonus, or an added benefit of entering the low inflation regime. $^{18}$

These dynamic properties of the estimated model are indeed economically sensible. An identical innovation in money generates a rising interest rate sooner during high inflationary periods than during low inflation periods. Furthermore, the preceding analysis indicates that interest rate has to rise by a large amount as the economy enters into a high inflation (regime) period after being in a low inflation period for awhile. That is, the net increase in the rate following an innovation in money during such a transition period is much larger than the increase in the rate caused by the same money innovation when high inflation has been in place throughout. This is intuitive because both a higher inflation expectation and inflation risk premia will be incorporated into interest rates for the first time during such a transition period. The converse holds. That is, the interest rate falls by a large amount with the onset of a low inflation period after a stretch of high inflation.

\footnotetext{
${ }^{18}$ One could interpret this result in the following way. Suppose the economy has been in a low inflation regime for awhile. Agents would accumulate a large real balance as the low inflation environment is favorable for holding money. Suppose the economy unexpectedly enters into a high inflation regime, which is expected to persist for a while. Then, everyone will try to reduce their real balance holdings. This will be possible only when there is a large run-up in price levels, perhaps more than what would be the case if the economy had been in an inflationary regime for the whole time. The deflationary case can be explained by the reverse of this scenario. That is, there will be a rush to build up real balances when the economy moves into a low inflation regime from a high inflation one, causing price levels to fall.
} 


\section{Discussion}

Two alternate interpretations seem most plausible--either the observed shift relationships mainly represent those in the monetary policy stance, or they represent shifts in what financial markets' perceived as the prevailing inflation regime. Suppose movements in the interest rate and nonborrowed reserves mostly represent the Fed's actions. In this case, the two regimes can be readily understood as capturing the inflationary tendency of monetary policy. That is, the stance of monetary policy is a key determinant of a higher average inflation rate associated with regime $\mathbf{H}$. Active intervention either to generate surprise changes in the funds rate, or to counter reserve demand shocks, could account for the high variability of regime $\mathbf{H}$. Accordingly, the converse will be true for regime $\mathbf{L}$. That is, both a less inflationary monetary policy stance and less active intervention to counter the reserve demand shocks describe the periods belonging to regime $\mathbf{L}$.

However, there seems to be seemingly obvious mismatches if we take this interpretation. For example, Figure 2 indicates that the period from early 1979 to the end of 1982 was governed by regime $\mathbf{H}$. According to historical evidence, substantial tightening of monetary policy seemed to have started much sooner than, say, 1982. Allowing some lag time in pattern recognition could explain such a mismatch. The estimated timing of regimes is based on a very limited information set, namely, histories of the interest rate changes and reserve innovations. Thus, for example, the model does not know that an increase in the volatility of the interest rate during the 1979-1982 period was mainly due to a suspension of interest rate smoothing pursued by the Fed throughout the 1970s. Therefore, interpreting periods of regimes $\mathbf{H}$ and $\mathbf{L}$ to be capturing the inflationary tendency of monetary policy 
warrants caution.

An alternative interpretation is that the two regimes might be capturing what financial markets perceive the prevailing inflation regime to be. For example, the yield on 30-year Treasury bonds rose only gradually until mid-1979, despite the fact that relatively high inflation prevailed throughout the preceding three years. The implicit price deflator rarely went below 7 percent during that period. This observation notwithstanding, the public might not have been sure about how long the spell was going to last (Goodfriend (1993)). This could explain why Figure 2 does not identify the late 1970s as a high inflation regime period.

On the other hand, there was a rapid run-up in the long rate in mid-1983 due to a serious 'inflation scare'. ${ }^{19}$ This set off the run-up in the funds rate to August 1984 . The rise in the model's estimate of the probability of high inflation regime being in place in 1984 could be partly explained by this chain of events.

Observations so far suggest that we need more structure to understand the nature of the regimes and their shifts. In particular, specifying the market for federal funds more explicitly should be useful if we are going to attribute the observed changes to those of the monetary policy stance per se (Coleman, Gilles and Labadie (1994) and Hamilton (1994)). Also, an identification scheme proposed in Leeper and Gordon (1995) that structurally distinguishes reserve supply and demand shocks might yield informative results.

However, the fact remains that regime $\mathbf{H}$ periods have a significantly higher average inflation rate compared to regime $\mathbf{L}$ periods. This suggests a weaker or narrower second

\footnotetext{
${ }^{19}$ Goodfriend (1983) defines the 'inflation scare' as a significant rise in long-rates in the absence of an aggressive funds rate tightening, thus mainly reflecting rising expected long-run inflation.
} 
interpretation. The two regimes represent two distinct environments, largely affected by the prevailing inflation trend.

\section{Conclusion}

This paper examined the potential influence of monetary policy regime changes on the liquidity effect in the context of a bivariate reduced form relationship. The stochastic regime switching model is able to capture some statistically and economically significant patterns that are distinct across the two posited regimes. Most significant is the identification of each regime with high and low inflation periods.

It's also shown that the divergence in the dynamic money-interest rate relationship across low and high inflation periods can be quite significant. Examinations of dynamic properties of the estimated model indeed yield economically sensible results. In general, a high inflation regime is associated with a stronger anticipated inflation effect. Furthermore, results indicate that the interest rate has to rise by a large amount as the economy enters into a high inflation (regime) period after being in a low inflation period for awhile. That is, the net increase in the rate following an innovation in money during such a transition period is much larger than the increase in the rate caused by the same money innovation when high inflation has been in place throughout. This is intuitive because both a higher inflation expectation and inflation risk premia will be incorporated into interest rates for the first time during such a transition period. The converse also holds. Given these findings, the potential regime shift wartants more attention in future empirical investigations of the liquidity effect.

However, the reduced form nature of the analysis puts a limit on answering further 
structural questions. Incorporating more structure in the model specification, parallel to the recent development in the conventional liquidity effect literature, might be necessary for stronger identification. 


\section{References}

Ammer, J., and A.D. Brunner, (1994), "U.S. Monetary Policy and Business Cycle Prediction Using a Switching-Regime Model," manuscript.

Boldin (1992), "Using Switching Models to Study Business Cycle Asymmetries: I. Overview of Methodology and Application," Federal Reserve Bank of New York Research Paper No. 9211.

Christiano, L.J. (1994), "Comment" on 'A Model of the Federal Funds Market,' by Coleman, Gilles and Labadie. manuscript.

Christiano, L.J., and M. Eichenbaum (1992), "Identification and the Liquidity Effect of a Monetary Policy Shock," in A. Cukierman,, Z. Hercowitz, and L. Leiderman, eds., Business Cycles, Growth and Political Economy, Cambridge, MA. MIT Press, pp. 335-370.

Evidence from the Flow of Funds," NBER Working Paper 4699.

, and C. Evans (1994), "The Effect of Monetary Policy Shocks:

Coleman, W. J., C. Gilles, and P. Labadie (1994), "A Model of the Federal Funds Market," manuscript.

Rates," Journal of Monetary Economics, 30, pp.449-465.

and (1992), "The Liquidity Premium in Average Interest

Filardo, A. J., (1994), "Business Cycle Phases and Their Transition Dynamics," Journal of Business and Economic Statistics 12, pp.299-308.

Fuerst, T.S., (1992), "Liquidity, Loanable Funds, and Real Activity," Journal of Monetary Economics 29, pp.3-24.

Garcia. R., (1992), "Asymptotic Null Distribution of the Likelihood Ratio Test in Markov Switching Models," working paper, University of Montreal.

Goodfriend, M., (1993), "Interest Rate Policy and the Inflation Scare Problem: 1979-1992," Economic Quarterly, Federal Reserve Bank of Richmond vol. 79.

Hamilton, J.D., (1994), "The Daily Market for Fed Funds," University of California, San Diego working paper. , (1994), Time Series Analysis, Princeton, NJ. Princeton University Press. 
, (1989), "A New Approach to the Economic Analysis of Nonstationary Time

Series and the Business Cycle," Econometrica 57, pp.357-384.

Hansen, B. E., (1993), "Inference When a Nuisance Parameter is Not Identified under the Null Hypothesis." University of Rochester. Mimeo.

Huh, C. G., (1995), "Regime Switching in the Dynamic Relationship between the Federal Funds Rate and Nonborrowed Reserves," working paper, Federal Reserve Bank of San Francisco.

Jefferson, P.N., (1994), "Qualitative and Quantitative Information and the Stance of Monetary Policy," working paper, University of California, Berkeley.

Kim, C. (1994), "Linear Dynamic Models with Markov-Switching," Journal of Econometrics, 60 , pp. $1-22$.

Leeper, E.M., and D. B. Gordon (1992), "In Search of Liquidity Effect," Journal of Monetary Economics 12, pp. 29-55.

, and , (1993), "The Dynamic Impacts of Monetary Policy: An Exercise in Tentative Identification," working paper, Federal Reserve Bank of Atlanta.

LeRoy, S.F., (1984), "Nominal Prices and Interest Rates in General Equilibrium: Money Shocks," Journal of Business 57, pp. 177-195.

Mishkin, F. S., (1992). "Is the Fisher Effect for Real?," Journal of Monetary Economics 30, pp. 195-215.

, (1982), "Monetary Policy and Short-term Interest Rates: An Efficient MarketsRational Expectations Approach," Journal of Finance 37, pp.63-72.

Reichenstein, W., (1987), "The Impact of Money on Short-term Interest Rates," Economic Inquiry 25, pp.67-82.

Pagan, A.R., and J.C. Robertson (1994), "Resolving the Liquidity Effect," manuscript.

Strongin, S., (1992), "The Identification of Monetary Policy Disturbances: Explaining the Liquidity Puzzle," Federal Reserve Bank of Chicago, WP 92-27.

Thornton, D.L., (1988), "The Effect of Monetary Policy on Short-Term Interest Rates" Federal Reserve Bank of St. Louis Review 70, pp.53-72. 


$$
r_{t}=\mu_{r}\left(s_{t}\right)+\sum_{j=1}^{4} \beta_{r}^{j}\left(s_{t}\right)\left[r_{t-j}-\mu_{r}\left(s_{t-j}\right)\right]+\sum_{i=0}^{3} \beta_{m}^{i}\left(s_{t}\right) u n b r_{t-i}+\epsilon_{t}\left(s_{t}\right)
$$

\begin{tabular}{|c|c|c|}
\hline Variable & Coefficients $(S=\mathrm{L})$ & Coefficients $(S=\mathbf{H})$ \\
\hline$\mu_{r}$ & $0.343 \quad(0.33)$ & $2.248(1.35)^{* *}$ \\
\hline$\beta^{0}{ }_{m}\left(S_{t}\right)$ & $-0.211(0.09)^{* * *}$ & $-1.426(0.69) * *$ \\
\hline$\beta^{\prime}{ }_{m}\left(S_{v}\right)$ & $-0.137(0.10)^{*}$ & $-0.105(1.31)$ \\
\hline$\beta_{m}^{2}\left(S_{J}\right)$ & $0.031(0.10)$ & $0.175 \quad(0.55)$ \\
\hline$\beta_{m}^{3}\left(S_{j}\right)$ & $-0.046(0.13)$ & $0.005 \quad(0.19)$ \\
\hline$\sigma^{2}$ & $4.198(0.41)$ & 74.249 (12.88) \\
\hline $\mathrm{p}$ & $0.975(0.01)$ & \\
\hline$q$ & & $0.906(0.04)$ \\
\hline Log likelihood & -594.71 & \\
\hline
\end{tabular}

***,**, and * respectively denote cases significant at 1,5 and 10 percent level. 


\begin{tabular}{|c|c|c|}
\hline \multicolumn{3}{|c|}{$r_{z}=\mu_{r}\left(s_{t}\right)+\sum_{j=1}^{4} \beta_{r}^{J}\left(s_{t}\right)\left[r_{t-j}-\mu_{r}\left(s_{t-j}\right)\right]+\sum_{i=0}^{s} \beta_{m}^{i}\left(s_{t}\right)\left[\eta_{t-i}-\mu_{m}\left(s_{t-i}\right)\right]+\epsilon_{t}\left(s_{t}\right)$} \\
\hline Variable & Coefficients $(S=\mathbf{L})$ & Coefficients $(S=\mathbf{H})$ \\
\hline$\mu_{r}=\mu_{m}$ & $0.259(0.18)^{*}$ & $14.25(3.14)^{* * *}$ \\
\hline$\beta^{0}{ }_{m}\left(S_{t}\right)$ & $-0.229(0.09)^{* * *}$ & $-0.004(0.10)$ \\
\hline$\beta^{1}{ }_{m}\left(S_{t}\right)$ & $-0.115(0.10)$ & $0.539(0.36)$ \\
\hline$\beta_{m}^{2}\left(S_{t}\right)$ & $0.023(0.09)$ & $-0.310(0.48)$ \\
\hline$\beta_{m}^{3}\left(S_{f}\right)$ & $0.042(0.08)$ & $0.658(0.35)^{* *}$ \\
\hline$\sigma^{2}$ & $4.40(0.46)$ & $75.75 \quad(14.84)$ \\
\hline $\mathrm{p}$ & $0.983(0.01)$ & \\
\hline$q$ & & $0.925(0.03)$ \\
\hline Log likelihood & -595.04 & \\
\hline
\end{tabular}

***, ${ }^{* *}$, and ${ }^{*}$ respectively denote cases significant at 1,5 and 10 percent level. 


\section{Figure 1: Supply and Demand for Nonborrowed Reserves, Two Regime World}

\section{FYFF}

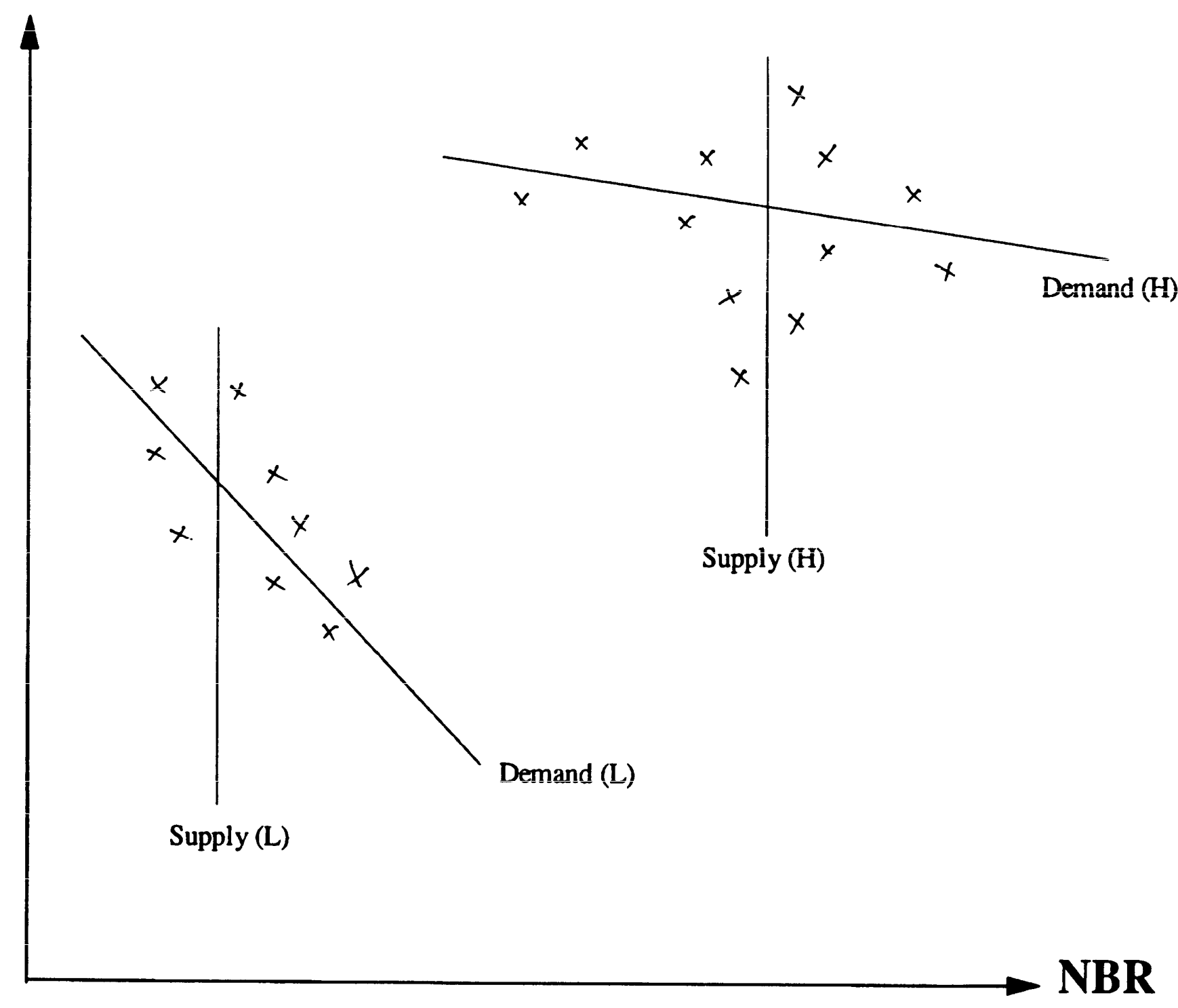




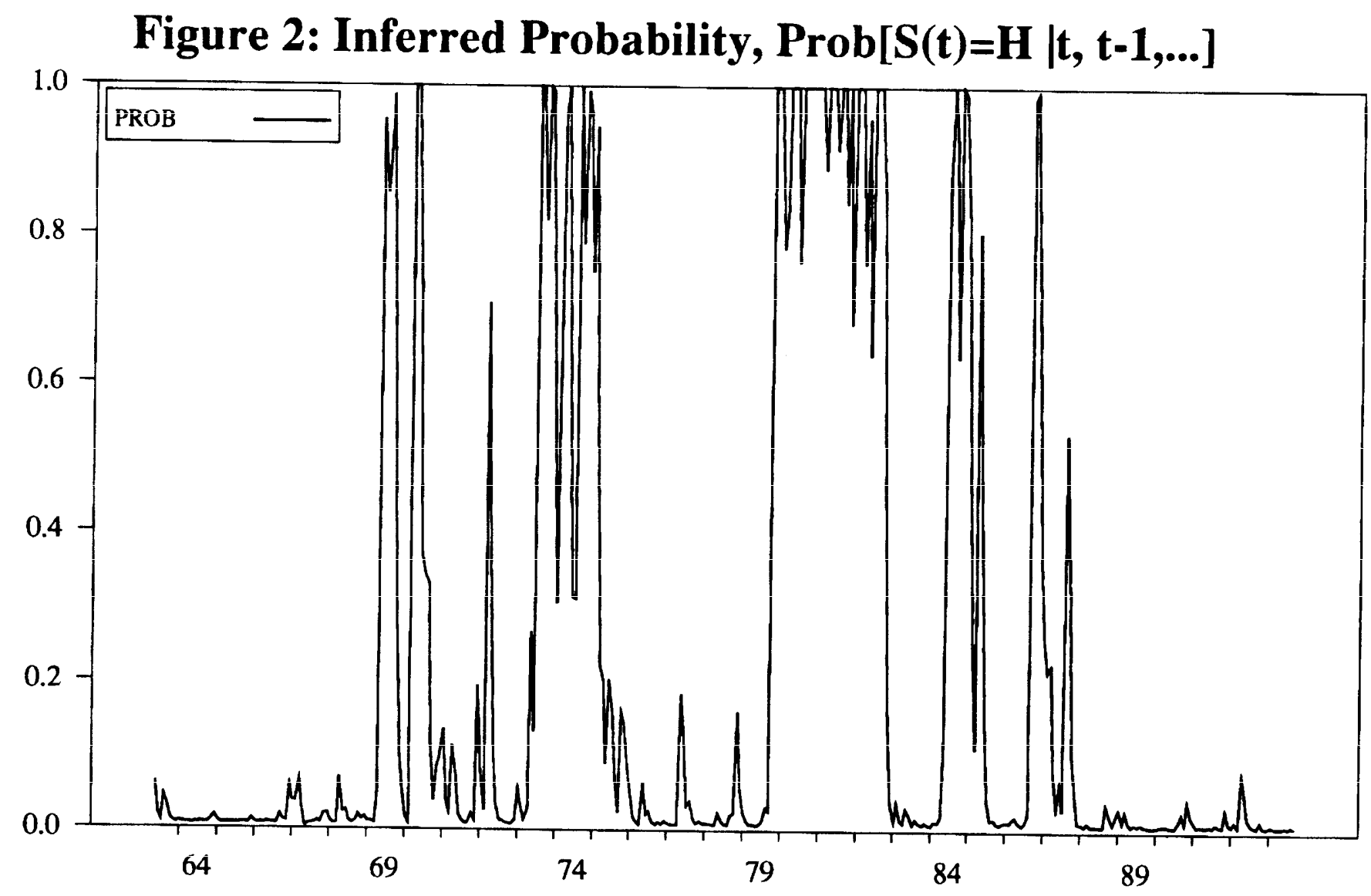

Figure 3: CPI Inflation and Inferred Probability (right scale)

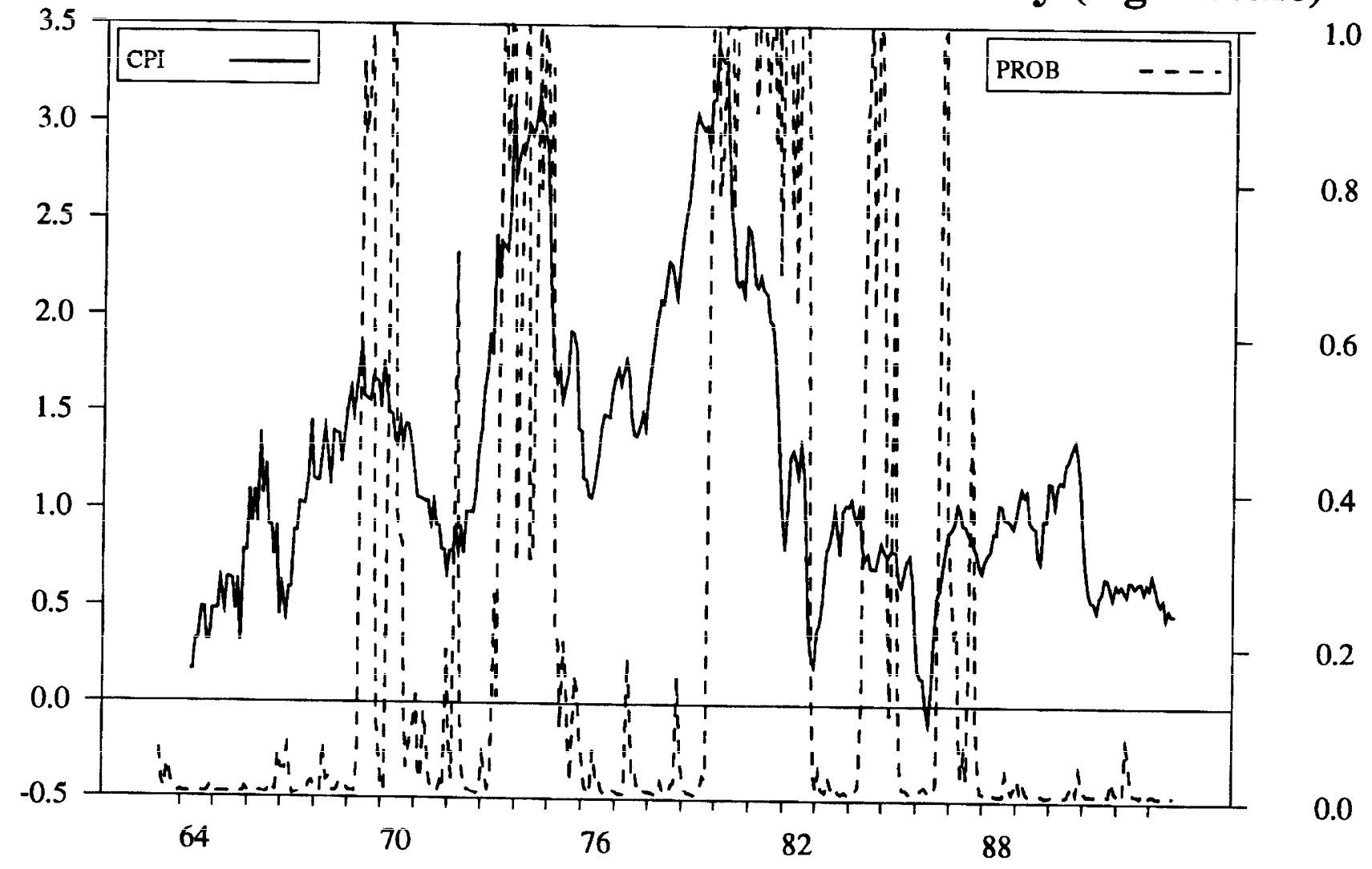




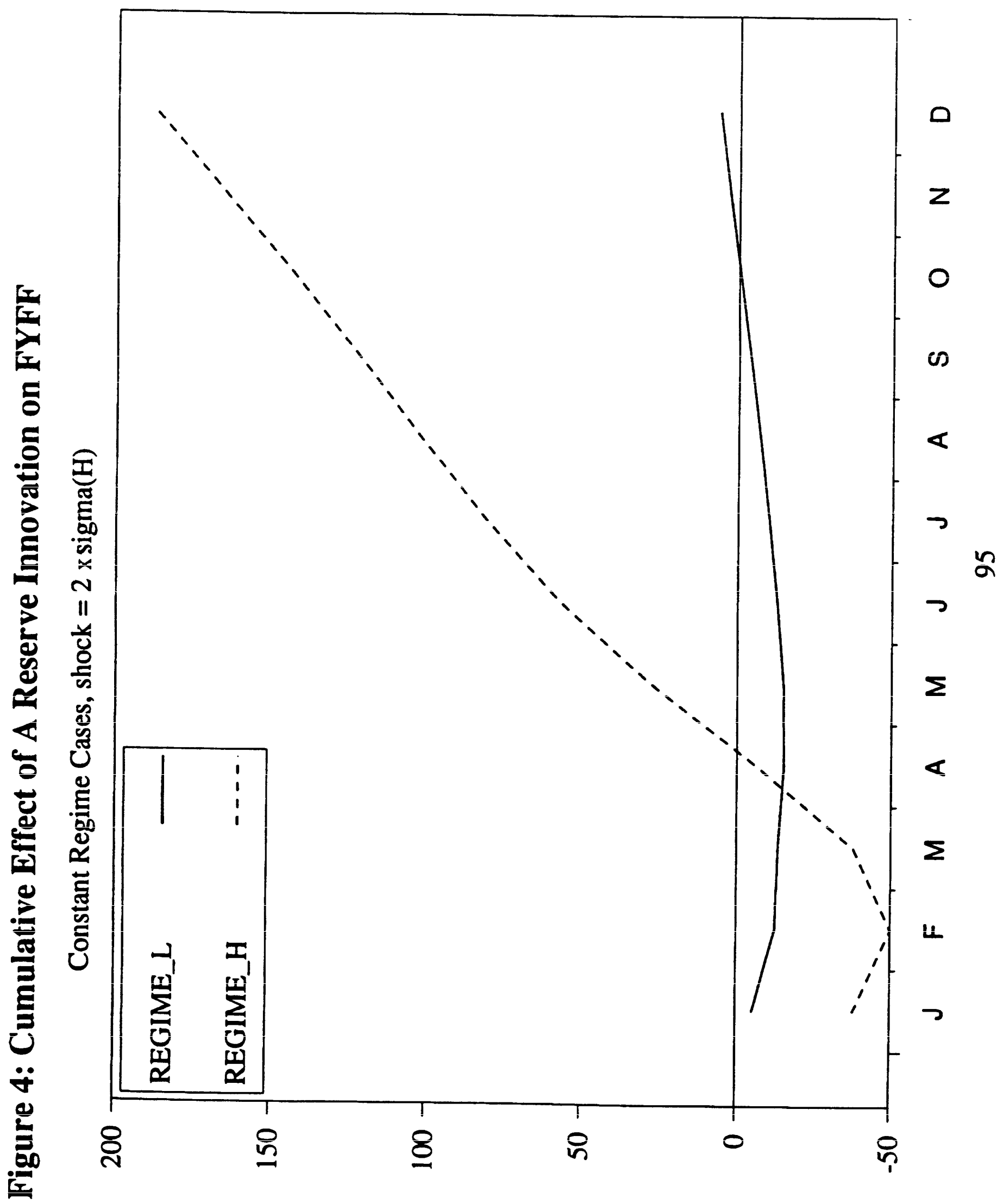


Figure 5: Cumulative Effect of One-time Reserve Innovation on FYFF; $S(t)=H$

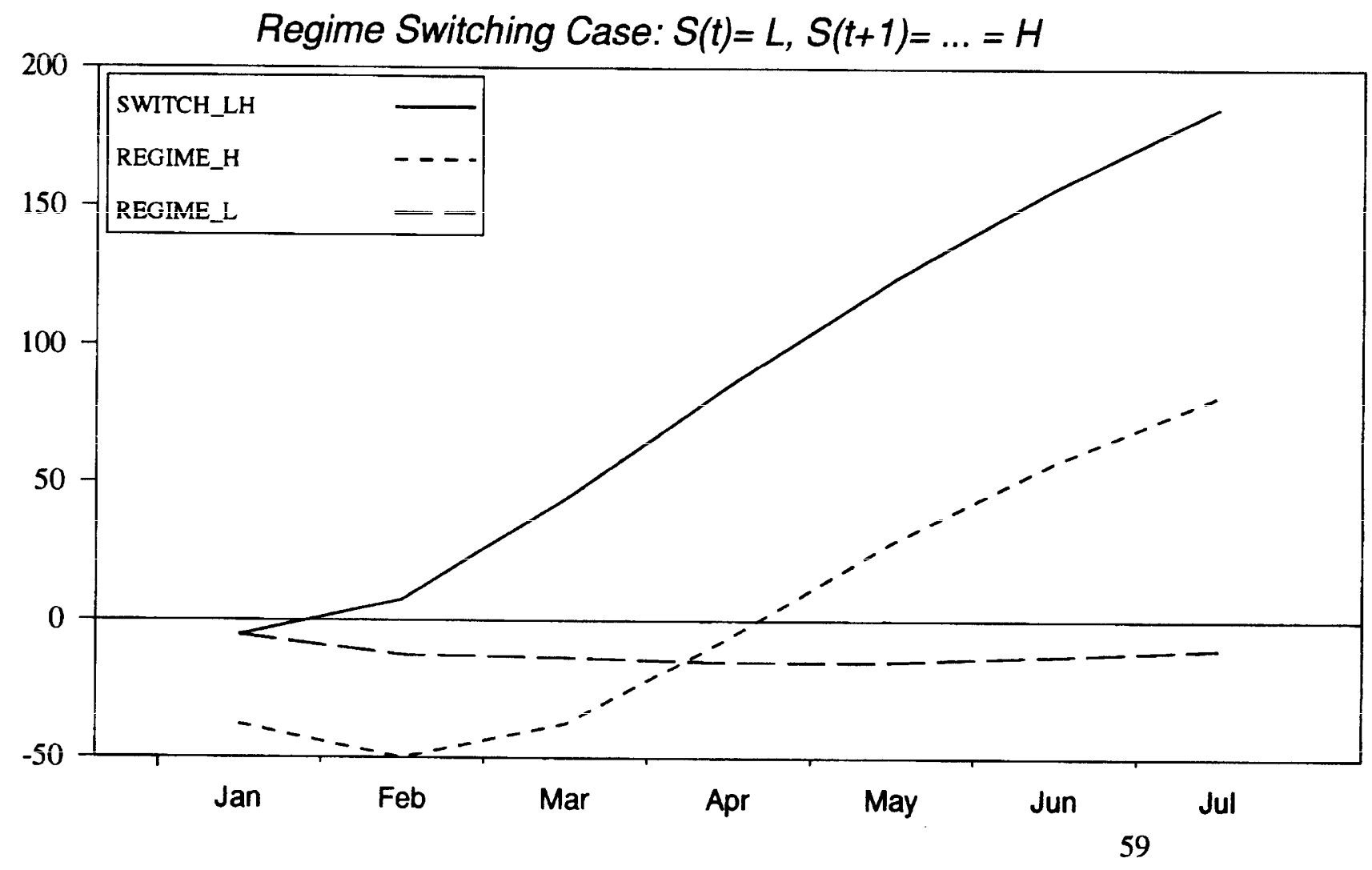

Figure 6: Cumulative Effect of One-time Reserve Innovation on FYFF; $S(t)=L$

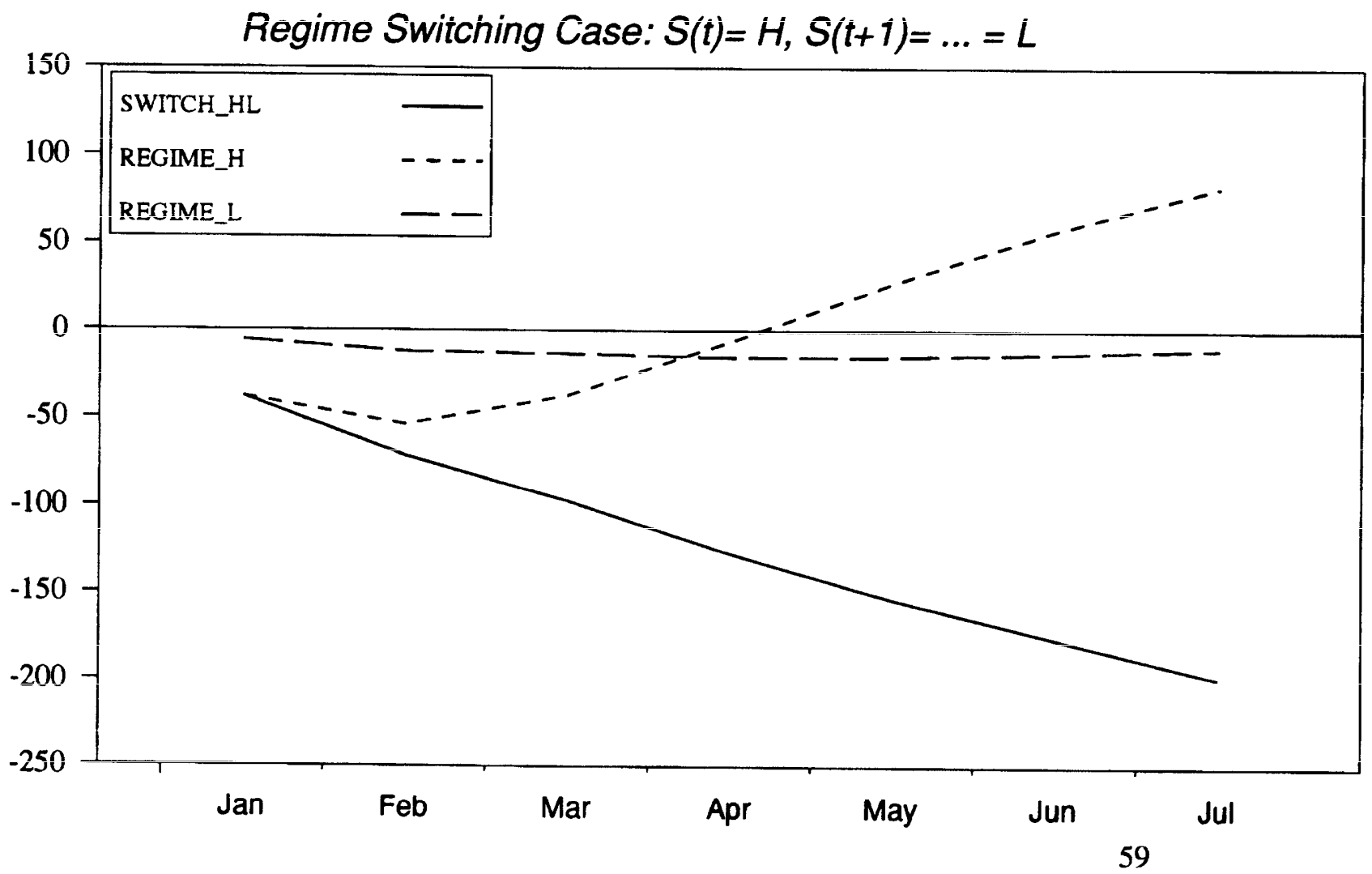




\section{Internationai Finance Discussion Papers}

IFDP

Number
Regime Switching in the Dynamic Relationship between the Federal Funds Rate and Innovations in Nonborrowed Reserves

535 The Risks and Implications of External Financial Shocks: Lessons from Mexico

534 Currency Crashes in Emerging Markets: An Empirical Treatment

533 Regional Patterns in the Law of One Price: The Roles of Geography vs. Currencies

1995

Titles

Author(s)

1996

Aggregate Productivity and the Productivity of Aggregates

Susanto Basu

John G. Fernald

Jaime Marquez

A Century of Trade Elasticities for Canada, Japan, and the United States

Modelling Inflation in Australia

Gordon de Brouwer

Neil R. Ericsson

Marcus Miller

Hyperinflation and Stabilisation: Cagan

Revisited

Lei Zhang

Guy V.G. Stevens

Portfolio Analysis

International Comparisons of the Levels of Unit

Labor Costs in Manufacturing

Peter Hooper

Elizabeth Vrankovich

Dale W. Henderson

Ning S. Zhu

of Nash Equilibrium: Microeconomic and

Macroeconomic Examples

Targeting Inflation in the 1990s: Recent Challenges
Richard T. Freeman

Jonathan L. Willis

Please address requests for copies to International Finance Discussion Papers, Division of International Finance, Stop 24, Board of Governors of the Federal Reserve System, Washington, DC 20551. 


\section{International Finance Discussion Papers}

IFDP

Number

Titles

Author(s)

1995

524 Economic Development and Intergenerational

Murat F. Iyigun

Economic Mobility

523 Human Capital Accumulation, Fertility and

Growth: A Re-Analysis

522 Excess Returns and Risk at the Long End of the Treasury Market: An EGARCH-M Approach

521 The Money Transmission Mechanism in Mexico

520 When is Monetary Policy Effective?

519 Central Bank Independence, Inflation and Growth in Transition Economies

Murat F. Iyigun

Allan D. Brunner

David P. Simon

Martina Copelman

Alejandro M. Werner

John Ammer

Allan D. Brunner

Prakash Loungani

Nathan Sheets

Hali J. Edison

Alternative Approaches to Real Exchange Rates and Real Interest Rates: Three Up and Three Down

William R. Melick

Vivek Ghosal

Prakash Loungani price uncertainty on investment: some evidence from U.S. manufacturing industries

516 Block Distributed Methods for Solving Multi-country Econometric Models

Jon Faust

Ralph Tryon

515 Supply-side sources of inflation: evidence

Prakash Loungani from OECD countries

Phillip Swagel

514 Capital Flight from the Countries in Transition:

Some Theory and Empirical Evidence

513 Bank Lending and Economic Activity in Japan: Did "Financial Factors" Contribute to the Recent Downturn?

512 Evidence on Nominal Wage Rigidity From a Panel of U.S. Manufacturing Industries

Nathan Sheets

Allan D. Brunner Steven B. Kamin

Vivek Ghosal

Prakash Loungani

511 Do Taxes Matter for Long-Run Growth?: Harberger's

Enrique G. Mendoza Superneutrality Conjecture

Gian Maria Milesi-Ferretti Patrick Asea 